\title{
Association between Epicondylitis and Cardiovascular Risk Factors in Pooled Occupational Cohorts
}

\author{
Kurt T. Hegmann 1*, Matthew S. Thiese1, Jay Kapellusch², Andrew Merryweather ${ }^{3}$, Stephen Bao ${ }^{4}$, \\ Barbara Silverstein ${ }^{4}$, Eric M. Wood ${ }^{1}$, Richard Kendall ${ }^{5}$, James Foster ${ }^{6}$, David L. Drury ${ }^{7}$ and Arun Garg ${ }^{2}$
}

\begin{abstract}
Background: The pathophysiology of lateral epicondylitis (LE) is unclear. Recent evidence suggests some common musculoskeletal disorders may have a basis in cardiovascular disease (CVD) risk factors. Thus, we examined CVD risks as potential LE risks.

Methods: Workers ( $n=1824$ ) were enrolled in two large prospective studies and underwent structured interviews and physical examinations at baseline. Analysis of pooled baseline data assessed the relationships separately between a modified Framingham Heart Study CVD risk score and three prevalence outcomes of: 1) lateral elbow pain, 2) positive resisted wrist or middle finger extension, and 3) a combination of both symptoms and at least one resisted maneuver. Quantified job exposures, personal and psychosocial confounders were statistically controlled. Odds ratios (ORs) and 95\% Confidence Intervals (Cls) were calculated.
\end{abstract}

Results: There was a strong relationship between CVD risk score and lateral elbow symptoms, resisted wrist or middle finger extension and LE after adjustment for confounders. The adjusted ORs for symptoms were as high as $3.81(95 \% \mathrm{Cl}$ $2.11,6.85)$, for positive examination with adjusted odds ratios as high as $2.85(95 \% \mathrm{Cl} 1.59,5.12)$ and for combined symptoms and physical examination $6.20(95 \% \mathrm{Cl} 2.04,18.82)$. Relationships trended higher with higher CVD risk scores.

Conclusions: These data suggest a potentially modifiable disease mechanism for LE.

\section{Background}

The prevalence, incidence, pathophysiology and risk factors of epicondylitis are inadequately defined. The reported prevalence rate of lateral epicondylitis (LE) ranges widely from $0.2 \%$ to $41.2 \%$ [1-18]. A few studies have estimated LE incidence rates based on either infrequent observations or clinic data with reported annual incidences ranging from $0.9-1.7 \%$, but likely underestimating the true incidence rates primarily due to the infrequency of observations [3, 19-21]. One study of workers from 10 employment settings, that include a minority of workers in this report, were followed monthly for up to 6 years reported a baseline point prevalence of $7.3 \%$, lifetime prevalence

\footnotetext{
* Correspondence: kurt.hegmann@hsc.utah.edu

${ }^{1}$ Rocky Mountain Center for Occupational and Environmental Health

(RMCOEH), School of Medicine, University of Utah, 391 Chipeta Way Suite C,

Salt Lake City, UT 84108, USA

Full list of author information is available at the end of the article
}

rate of $17.2 \%$ and an incidence rate of 3.67 per 100 person-years [22]. An incidence rate as high as $11.3 \%$ has been reported [23]. These wide-ranging estimates may be partially explained by heterogeneity of study methods including differences in intensity of surveillance methods, populations studied, and case definitions.

The pathophysiology of LE is also unclear, with purportedly several competing explanatory pathophysiological findings. These include: hyperlaxity [24], posterolateral rotatory instability [25], myofascial pain [26], trigger points [26, 27] and extensor carpi radialis longus tears and granulation tissue [28-33]. As the pathophysiology is unclear, it may be unsurprising that physical examination findings, treatment options and surgical techniques vary considerably and at times appear contradictory, e.g., beneficial effects of rest vs. exercise, botulinum injections vs. exercise, and ligament cutting vs. aponeurotic release [10, 27, 29, 34-38]. 
Longitudinal studies suggest increasing age [12, 19, 39-41], and obesity [19] may be LE risk factors. Longitudinal data also suggest low social support [19,42] and depression [41] are risks, although one study found no increased risk attributable to low social support [4]. Genetic factors are also reportedly risks $[43,44]$.

There are longstanding reports that LE is associated with forceful athletic use [45-51], although the study methods used have mostly been retrospective. Job physical factors have been largely evaluated by self-report and/or in retrospective studies $[1,2,9,12,16-18,20,39,41,52-62]$. Such methods are prone to produce associations based on "common beliefs" that are not likely to be dispositive regarding determinations of true risk factors. Thus, the mechanistic understanding of LE is fairly primitive.

A systematic review reported that shoulder pain is associated with CVD risk factors [63]. A recent publication also suggested CVD risks are carpal tunnel syndrome (CTS) risks with odds ratios over 5 -fold for CTS and over 8 -fold for abnormal median nerve conduction [30].

The purpose of this study is to evaluate the potential for association(s) between cardiovascular disease risk factors and LE separately in a large pooled study of three prospective cohort studies involving systematic data collected from over 1800 workers in 35 workplaces in 4 US states.

\section{Methods}

This report is of the baseline, cross sectional data for these prospective cohort studies. Institutional Review Boards approved the study at the University of Utah (11889), the University of Wisconsin-Milwaukee (\#03.02.059) and the State of Washington (A-050900-L). Data were collected from 2002 to 2006 and data analysis was conducted in 2015 and 2016.

Worker recruitments were conducted at 35 facilities involving 25 diverse industries located in the states of Illinois, Utah, Washington and Wisconsin beginning in 2001 through 2007. Industries included were manufacturing, food processing, and office jobs. Workers were consented. Workers were recruited regardless of the presence or absence of symptoms until pre-determined enrollment targets based on sample size calculations were met. The only exclusions were marked hand deformities and severe inflammatory arthritides.

Health data were collected by the Health Outcomes Assessment Teams using computerized questionnaires and structured interviews. Standardized physical examinations were conducted. Questionnaire data included age, gender, hobbies, exercise habits, job satisfaction, depression symptoms, diabetes mellitus, and hypertension. Structured interviews utilized symptoms diagrams for anatomically localizing pain. The presence and distribution of pain was captured by location. Body mass indices
(BMIs) were calculated from measured heights and weights. Blood pressure was measured using automatic cuffs after being seated for at least five minutes (Omron HEM-780).

Data collected for this study's health outcomes on all subjects regardless of symptoms were: (i) lateral elbow pain, (ii) resisted wrist extension and/or resisted middle finger extension, and (iii) a case definition for LE that required both lateral elbow pain and at least one of the two positive resisted examination maneuvers.

Job Evaluation Teams measured and videotaped the worker's job(s). Jobs were measured for six primary factors: force, repetition rate, duration of exertion, posture, speed of work, and task duration per day. Strain Index scores, a composite measure of physical job strain, were computed from those six factors [64-66].

Framingham Heart Study's heart disease risk model is a sex-specific model that incorporates multiple cardiovascular disease risk factors that have been validated as predictive of 10-year risk of coronary artery disease: age, sex, hypertension, systolic blood pressure, smoking, total cholesterol and HDL cholesterol [67]. For the Framingham model, point values, stratified by gender, were assigned for variables of age, treated and untreated measured or self-reported past diagnosis of hypertension, tobacco use and diabetes mellitus (Table 1). Modified values were used as blood pressure was measured for participants in Illinois, Utah and Wisconsin (Washington did not measure blood pressure, $n=749$ missing measurements), and cholesterol was excluded from the scoring as it was not measured. Workers without a blood pressure measurement but with a history of hypertension were conservatively assigned a blood pressure value of 1 point. Each worker's CVD risk score was calculated by summing the individual CVD variable point values. Individualized CVD risk scores range from 0 to 29. An a priori decision was made without knowledge of the relationships to LE to collapse scores $\geq 16$ into one category, as scores above 16 were too infrequent to provide accurate statistical power. Additional analyses of the risk from the Framingham risk model on the Illinois, Utah and Wisconsin data were performed that included blood pressure measurements, hypertensive history and cholesterol history.

\section{Statistical analyses}

The risk between individualized CVD risk score was analyzed separately for the three health outcomes prevalences of (i) lateral elbow pain, (ii) at least one resisted examination maneuver and (iii) LE using logistic regression. These are hereafter referred to as pain, examination findings and LE, respectfully. Missing data were minimized by using computerized instruments. Univariate analyses were done with each variable individually to conclude separate associations with each of the three health outcomes and 
Table 1 Modified Framingham risk profiles by gender

\begin{tabular}{|c|c|c|c|c|c|c|}
\hline Score & Age, $y$ & High Cholesterol & Systolic BP + No High BP diagnosis & Systolic BP + Yes High BP diagnosis & Tobacco use & Diabetes \\
\hline \multicolumn{7}{|c|}{ CVD Risk Scores for Women } \\
\hline 0 & $\leq 34.9$ & No & $<130$ & $<120$ & No & No \\
\hline 1 & & & 130-139 & & & \\
\hline 2 & $35-39.9$ & & $140-149$ & $120-129$ & & \\
\hline 3 & & Yes & & 130-139 & Yes & \\
\hline 4 & $40-40.9$ & & $150-159$ & & & Yes \\
\hline 5 & $45-49.9$ & & $\geq 160$ & $140-149$ & & \\
\hline 6 & & & & $150-159$ & & \\
\hline 7 & $50-54.9$ & & & $\geq 160$ & & \\
\hline 8 & $55-59.9$ & & & & & \\
\hline 9 & $60-64.9$ & & & & & \\
\hline 10 & $65-69.9$ & & & & & \\
\hline 11 & $70-74.9$ & & & & & \\
\hline 12 & $\geq 75$ & & & & & \\
\hline \multicolumn{7}{|c|}{ CVD Risk Scores for Men } \\
\hline 0 & $\leq 34.9$ & No & $<130$ & $<120$ & No & No \\
\hline 1 & & & 130-139 & & & \\
\hline 2 & $35-39.9$ & Yes & $140-159$ & $120-129$ & & \\
\hline 3 & & & $\geq 160$ & 130-139 & & Yes \\
\hline 4 & & & & 140-159 & Yes & \\
\hline 5 & $40-40.9$ & & & $\geq 160$ & & \\
\hline 6 & $45-49.9$ & & & & & \\
\hline \multicolumn{7}{|l|}{7} \\
\hline 8 & $50-54.9$ & & & & & \\
\hline \multicolumn{7}{|l|}{9} \\
\hline 10 & $55-59.9$ & & & & & \\
\hline 11 & $60-64.9$ & & & & & \\
\hline 12 & $65-69.9$ & & & & & \\
\hline \multicolumn{7}{|l|}{13} \\
\hline 14 & $70-74.9$ & & & & & \\
\hline 15 & $\geq 75$ & & & & & \\
\hline
\end{tabular}

CVD cardiovascular disease, $B P$ blood pressure, $\mathrm{mmHg}$ Points allotted based on the Framingham Heart Study CVD risk tables

then combined in a multivariate logistic regression to assess the influence of confounders for each health outcome. Statistical significance is $p<0.05$. Variables with meaningful evidence of associations with LE $(p<0.20)$ were considered for inclusion in multivariate models as potential confounders. These potential confounders included job physical exposures (Strain Index for the typical job task on the right hand), BMI, and job satisfaction. Assessments were made for collinearity between potential confounders. The final main effects model included all confounders that were statistically significant or had an epidemiological basis for a causal relationship and were trending toward statistical significance $(p<0.20)$.

\section{Results}

The population consisted of 1824 workers, of which 1088 (59.6\%) were female (see Table 2). The mean age was $41.1 \pm 11.4$ years. Minorities of workers had diabetes mellitus $(n=86,4.7 \%)$, hypertension $(n=288$, $15.8 \%)$, and had ever smoked $(729,40.0 \%)$. The mean body mass index was $28.7 \pm 6.5 \mathrm{~kg} / \mathrm{m}^{2}$.

A total of 273 (15.0\%) had lateral elbow symptoms at baseline. A positive examination finding of either resisted wrist extension or resisted middle finger extension was present in 264 (14.5\%). Lateral epicondylitis, defined by both lateral elbow symptoms and a resisted examination maneuver, was present in 121 (6.6\%), which is this population's point prevalence rate. 
Table 2 Descriptive and demographic data of the pooled studies at baseline $(n=1824) \mathrm{N}(\%)$

\begin{tabular}{|c|c|c|c|c|c|}
\hline Variable $^{a}$ & $\begin{array}{l}\text { Symptoms at time } \\
\text { of exam }{ }^{\text {b }}\end{array}$ & $\begin{array}{l}\text { Positive exam } \\
\text { findings }^{c}\end{array}$ & $\begin{array}{l}\text { Lateral epicondylitis } \\
\text { (symptoms and exam) }^{\text {d }}\end{array}$ & $\begin{array}{l}\text { No lateral } \\
\text { epicondylitis }\end{array}$ & Total \\
\hline$(N=)$ & $(n=273,15.0 \%)$ & $(n=264,14.5 \%)$ & $(n=121,6.6 \%)$ & $n=1703,93.4 \%)$ & $(n=1824,100 \%)$ \\
\hline Age (years) & $43.4(9.6)$ & $43.6(9.8)$ & $44.5(8.6)$ & $40.9(11.5) p=0.001$ & $41.1(11.4)$ \\
\hline Gender & & & & $p=0.008$ & \\
\hline Female & 199 (72.9\%) & $183(69.3 \%)$ & $86(71.1 \%)$ & $1002(58.8 \%)$ & $1088(59.6 \%)$ \\
\hline Male & $74(27.1 \%)$ & 81 (30.7\%) & 35 (28.9\%) & $701(41.2 \%)$ & $736(40.4 \%)$ \\
\hline Diabetes Mellitus & & & & $p=0.144$ & \\
\hline Yes & $18(6.6 \%)$ & 15 (5.7\%) & $9(7.4 \%)$ & 77 (4.5\%) & $86(4.7 \%)$ \\
\hline No & $255(93.4 \%)$ & $249(94.3 \%)$ & $112(92.6 \%)$ & $1626(95.5 \%)$ & 1738 (95.3\%) \\
\hline Hypertension & & & & $p=0.207$ & \\
\hline Yes & $43(15.8 \%)$ & $50(18.9 \%)$ & $24(19.8 \%)$ & $264(15.5 \%)$ & $288(15.8 \%)$ \\
\hline No & $230(84.2 \%)$ & $214(81.1 \%)$ & 97 (80.2\%) & 1439 (84.5\%) & $1536(84.2 \%)$ \\
\hline Average systolic Blood Pressure (mmHg) & $128.9(17.9)$ & $128.2(17.8)$ & $130.0(18.7)$ & $12.5(17.1) p=0.518$ & $127.7(17.2)$ \\
\hline Tobacco Use & & & & $p=0.097$ & \\
\hline Never & $152(55.7 \%)$ & $155(58.7 \%)$ & $64(52.9 \%)$ & $1031(60.5 \%)$ & $1095(60.0 \%)$ \\
\hline Ever & $121(44.3 \%)$ & $109(41.3 \%)$ & $57(47.1 \%)$ & $672(39.5 \%)$ & $729(40.0 \%)$ \\
\hline Body Mass Index (kg/m2) & $29.8(6.7)$ & $28.5(6.7)$ & $29.4(6.7)$ & $28.6(6.5) p=0.157$ & $28.7(6.5)$ \\
\hline CVD Risk Score & $6.8(3.9)$ & $6.6(3.9)$ & $7.3(4.0)$ & $5.8(4.2) p=0.0003$ & $5.9(4.2)$ \\
\hline
\end{tabular}

${ }^{\mathrm{a}} \mathrm{N}(\%)$ for categorical variables. Mean (Standard Deviation) for continuous variables

bLateral elbow pain

${ }^{c}$ Either lateral elbow pain with resisted wrist extension or middle finger extension

${ }^{d}$ Case definition of lateral epicondylitis with both Lateral elbow pain and at least one resisted wrist physical examination maneuver

The mean age was greater among those with symptoms, examination findings or having LE (OR per year $=1.02$, $p<0.0004,1.02 p<0.0001$, and 1.03, $p<0.001$ respectively). The population had more females than males $(n=1088$, $59.6 \%)$, and modestly higher risk of LE with female sex $\mathrm{OR}=1.72,95 \%$ CI 1.15, $2.58(p=0.008)$. Diabetes mellitus was present in $86(4.7 \%)$, but was present in $7.4 \%$ in those with $\mathrm{LE}(\mathrm{OR}=1.70,95 \% \mathrm{CI} 0.83,3.47, p=0.148)$. Hypertension was present in 288 (15.8\%) and modestly more common among those with $\mathrm{LE}(\mathrm{OR}=1.35,95 \% \mathrm{CI} 0.85,2.15)$. Among the 1075 participants who had measured blood pressure, the systolic blood pressure was somewhat higher in the LE case group $130.0 \pm 18.7 \mathrm{mmHg}$ compared with the non-LE case group at $127.5 \pm 17.1 \mathrm{mmHg}$. The Body Mass Index (BMI) was higher in the LE group 29.4 \pm 6.7 compared with the non-LE case group's BMI of $28.6 \pm 6.5 \mathrm{~kg} / \mathrm{m}^{2}$. The overall mean individualized CVD risk score was higher in the LE case group $7.3 \pm 4.0$ compared with the non-LE case group $5.8 \pm 4.2$ $(p=0.0003)$.

Data were analyzed to assess associations between the person's CVD risk factor score and risk of lateral elbow pain, examination findings and LE (see Table 3). Separate analyses assessed relationships between CVD risk factor scores and 1) lateral elbow pain regardless of test findings, 2) at least one positive physical examination test result (either resisted middle finger or wrist extension) and 3) LE as defined by both symptoms and at least one positive physical examination test result. For unadjusted associations, there was a trend of increasing risk for both LE symptoms and positive test result with CVD risk factor scores peaking at odds ratios of 3.61 (95\% CI 2.02, $6.47)$ and 2.81 (95\% CI 1.57, 5.01), respectively. For analyses of risk for LE, the results showed mostly stronger associations than for symptoms or examination test alone and peaked at an odds ratio of 6.62 (95\% CI 2.21, $19.80)$. Body mass indices were significantly related to LE symptoms. The Strain Index scores that assessed job physical demands were significantly related to positive physical examination test results in the univariate analyses. Job dissatisfaction had significant univariate association with both LE symptoms and LE, but not with positive physical examination test results.

Adjusted analyses were performed that included BMIs, Strain Index scores and job satisfaction (see Table 4). These results were largely comparable to the unadjusted rates. Risk of LE rose across the cardiovascular disease risk scores in a highly significant trend $(p=0.0005)$ (see Fig. 1). The peak risk of LE was an OR of 6.20 (95\% CI 2.04, 18.8). The point estimates were lower for either symptoms alone or physical examination findings alone. BMIs were not significantly associated with LE. Strain Index was borderline associated. Job satisfaction remained significant with those 
Table 3 Crude OR $(95 \%$ Cl) for right lateral elbow symptoms, right lateral elbow physical examination maneuvers and right lateral epicondylitis*

\begin{tabular}{|c|c|c|c|}
\hline Crude Analyses & Lateral Elbow Symptoms & $\begin{array}{l}\text { Positive Resisted Elbow } \\
\text { or Middle Finger Extension }\end{array}$ & $\begin{array}{l}\text { Lateral Epicondylitis (Symptoms plus } \\
\text { at least one Exam Maneuver) }\end{array}$ \\
\hline Framingham score & OR $(95 \% \mathrm{Cl})$ & OR $(95 \% \mathrm{Cl})$ & OR $(95 \% \mathrm{Cl})$ \\
\hline 0 & 1.00 (Reference) & & 1.00 (Reference) \\
\hline 1 & $0.77(0.17,3.43)$ & $0.34(0.04,2.58)$ & N/A \\
\hline 2 & $2.13(1.09,4.15)$ & $1.80(0.93,3.51)$ & $3.62(1.26,10.4)$ \\
\hline 3 & $2.05(0.98,4.28)$ & $1.22(0.54,2.75)$ & $2.65(0.79,8.88)$ \\
\hline 4 & $1.58(0.85,2.92)$ & $2.21(1.26,3.88)$ & $2.03(0.71,5.79)$ \\
\hline 5 & $2.47(1.37,4.46)$ & $2.33(1.31,4.13)$ & $4.60(1.78,11.9)$ \\
\hline 6 & $2.68(1.35,5.33)$ & $1.77(0.86,3.64)$ & $4.18(1.41,12.4)$ \\
\hline 7 & $3.43(1.89,6.23)$ & $2.04(1.09,3.81)$ & $3.45(1.23,9.69)$ \\
\hline 8 & $3.61(2.02,6.47)$ & $2.81(1.57,5.01)$ & $4.91(1.86,12.9)$ \\
\hline 9 & $2.46(1.22,4.93)$ & $2.23(1.12,4.42)$ & $4.14(1.40,12.2)$ \\
\hline $10-12$ & $1.99(1.12,3.53)$ & $1.99(1.15,3.45)$ & $3.19(1.23,8.29)$ \\
\hline $13-15$ & $2.62(1.35,5.10)$ & $2.08(1.06,4.07)$ & $4.64(1.64,13.1)$ \\
\hline $16+$ & $2.89(1.34,6.24)$ & $2.36(1.08,5.13)$ & $6.62(2.21,19.8)$ \\
\hline Per Unit for Framingham & $1.05(1.02,1.08)$ & $1.05(1.02,1.08)$ & $1.08(1.03,1.12)$ \\
\hline Body Mass Index & $1.03(1.01,1.05)$ & $0.99(0.97,1.02)$ & $1.02(0.99,1.05)$ \\
\hline Strain Index & $1.00(0.99,1.01)$ & $0.98(0.96,0.99)$ & $0.98(0.95,1.00)$ \\
\hline \multicolumn{4}{|l|}{ Job satisfaction } \\
\hline Satisfied & 1.00 (Reference) & 1.00 (Reference) & 1.00 (Reference) \\
\hline Neither satisfied or Dissatisfied & $1.62(1.16,2.25)$ & $1.22(0.89,1.67)$ & $1.80(1.10,2.94)$ \\
\hline Dissatisfied & $2.06(1.40,3.02)$ & $1.26(0.86,1.84)$ & $2.01(1.14,3.54)$ \\
\hline
\end{tabular}

OR Odds ratios, C Confidence interval, RLES right lateral elbow symptoms, RLE Right lateral epicondylitis

*The physical exam consisted of either a resisted wrist or middle finger extension. RLE was based on combined symptoms and at least one resisted maneuver

dissatisfied having 2.34-fold risk of having LE (95\% CI $1.31,4.17)$.

Adjusted analyses were also performed on the subset of Illinois, Utah and Wisconsin data that included blood pressure measurements, hypertensive histories and cholesterol histories. (See Table 5.) Those analyses revealed elevated risks for lateral elbow symptoms with a peak OR of $5.71(95 \%$ CI 2.32, 14.07) and a peak OR for a positive physical examination maneuver of 4.09 (95\% CI $1.31,12.79)$. The peak risk for lateral epicondylitis was an OR of 8.60 (95\% CI 2.17, 34.02).

\section{Discussion}

This large, multi-plant, multi-state study found significantly elevated risks of lateral epicondylitis (LE) associated with cardiovascular disease risk factors after adjusting for job physical factors, BMI, and job satisfaction. The magnitude of the association is as high as 6-fold with a strong trend across the CVD risk scores $(p=0.0005)$. This evidence adds to a growing body of evidence that common, soft-tissue musculoskeletal disorders, including shoulder disorders, Achilles tendinopathy, and carpal tunnel syndrome [30, 63, 68, 69], may have pathophysiological bases in CVD risks. A discrete mechanism of action of CVD risk is clearer in the shoulder and Achilles where tenuous blood supply to the tendons is well defined [70-74]. For CTS and lateral epicondylitis, it may be that the CVD risk is similarly associated with reduced blood supply, which increases susceptibility to biomechanical and other factors.

This study found that the individual risk factors that compose the Framingham model (e.g., tobacco, diabetes mellitus, and hypertension) were mostly trending towards significance. That the overall CVD risk factor modeling results that included those same Framingham individual risk factors are so strong suggests the CVD risk factors interact, as is well reported in cardiovascular disease, and thus do meaningfully influence the development of $\operatorname{LE}[75,76]$.

Additionally, that the weaker associations with CVD risks for the lateral elbow symptoms and physical examination findings compared to LE are expected and consistent. A principle of epidemiological research is that the more precise a diagnosis, the stronger is the ability to find effects $[77,78]$. The findings for the two other 
Table 4 Adjusted* OR (95\% Cl) for right lateral elbow symptoms, right lateral elbow physical examination maneuvers and right lateral epicondylitis**

\begin{tabular}{|c|c|c|c|}
\hline Adjusted analyses & Lateral Elbow Symptoms & $\begin{array}{l}\text { Positive Resisted Elbow } \\
\text { or Middle Finger Extension }\end{array}$ & $\begin{array}{l}\text { Lateral Epicondylitis (Symptoms plus } \\
\text { at least one Exam Maneuver) }\end{array}$ \\
\hline Framingham score & OR $(95 \% \mathrm{Cl})$ & OR $(95 \% \mathrm{Cl})$ & OR $(95 \% \mathrm{Cl})$ \\
\hline 0 & 1.00 (Reference) & 1.00 (Reference) & 1.00 (Reference) \\
\hline 1 & $0.69(0.15,3.12)$ & $0.35(0.05,2.66)$ & N/A \\
\hline 2 & $2.18(1.11,4.28)$ & $1.86(0.95,3.63)$ & $3.76(1.30,10.9)$ \\
\hline 3 & $1.87(0.89,3.92)$ & $1.26(0.56,2.84)$ & $2.59(0.77,8.73)$ \\
\hline 4 & $1.57(0.85,2.92)$ & $2.27(1.29,3.98)$ & $2.06(0.72,5.91)$ \\
\hline 5 & $2.54(1.40,4.61)$ & $2.36(1.33,4.20)$ & $4.69(1.80,12.2)$ \\
\hline 6 & $2.58(1.29,5.16)$ & $1.78(0.86,3.69)$ & $4.10(1.38,12.2)$ \\
\hline 7 & $3.45(1.89,6.29)$ & $2.10(1.12,3.92)$ & $3.51(1.24,9.89)$ \\
\hline 8 & $3.81(2.11,6.85)$ & $2.85(1.59,5.12)$ & $5.08(1.92,13.4)$ \\
\hline 9 & $2.53(1.25,5.11)$ & $2.32(1.16,4.64)$ & $4.34(1.45,12.9)$ \\
\hline $10-12$ & $1.95(1.10,3.49)$ & $2.05(1.18,3.57)$ & $3.22(1.24,8.41)$ \\
\hline $13-15$ & $2.33(1.18,4.58)$ & $2.13(1.08,4.21)$ & $4.35(1.52,12.4)$ \\
\hline \multirow[t]{2}{*}{$16+$} & $2.57(1.18,5.61)$ & $2.42(1.10,5.31)$ & $6.20(2.04,18.8)$ \\
\hline & $1.05(1.02,1.09)$ & $1.05(1.02,1.08)$ & $1.08(1.03,1.13)$ \\
\hline Body Mass Index & $1.03(1.01,1.05)$ & $0.99(0.97,1.01)$ & $1.01(0.98,1.04)$ \\
\hline Strain Index & $1.00(0.99,1.01)$ & $0.98(0.96,0.99)$ & $0.97(0.95,1.00)$ \\
\hline \multicolumn{4}{|l|}{ Job satisfaction } \\
\hline Satisfied & 1.00 (Reference) & 1.00 (Reference) & 1.00 (Reference) \\
\hline Neither satisfied or Dissatisfied & $1.64(1.17,2.29)$ & $1.26(0.92,1.74)$ & $1.86(1.13,3.06)$ \\
\hline Dissatisfied & $2.23(1.51,3.30)$ & $1.42(0.96,2.10)$ & $2.34(1.31,4.17)$ \\
\hline
\end{tabular}

OR Odds ratios, C Confidence interval, RLES right lateral elbow symptoms, RLE Right lateral epicondylitiss

*Adjusted for variables in the table, i.e., Framingham score, body mass index, Strain Index (measure of job physical demand). **The physical exam consisted of either a resisted wrist or middle finger extension. RLE was based on combined symptoms and at least one resisted maneuver

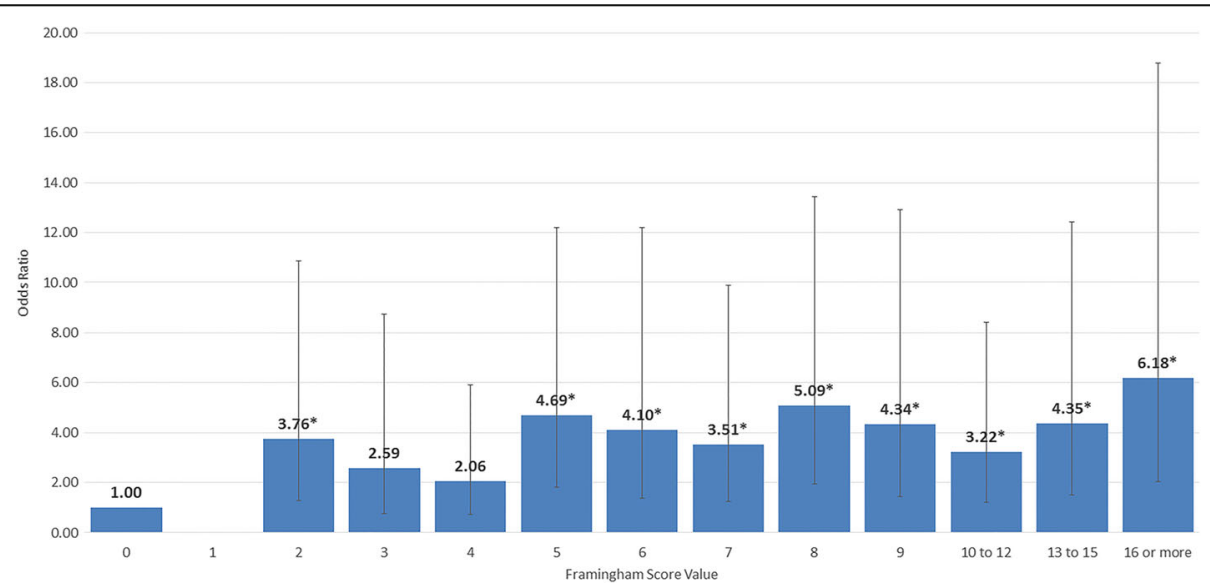

Fig. 1 Odds ratios and 95\% confidence intervals for lateral epicondylitis by cardiovascular disease risk score adjusted for body mass index, strain index and job satisfaction 
Table 5 Risk of lateral elbow symptoms and lateral epicondylitis associated with Framingham risk scores

\begin{tabular}{llll}
\hline $\begin{array}{l}\text { Framingham } \\
\text { score }\end{array}$ & $\begin{array}{l}\text { OR }(95 \% \mathrm{Cl}) \text { for } \\
\text { current symptoms }\end{array}$ & $\begin{array}{l}\text { OR }(95 \% \mathrm{Cl}) \\
\text { for physical } \\
\text { exam maneuver }\end{array}$ & $\begin{array}{l}\text { OR }(95 \% \mathrm{Cl}) \text { for case } \\
\text { definition of lateral } \\
\text { epicondylitis }\end{array}$ \\
\hline 0 & 1.00 (Reference & $\begin{array}{l}1.00 \text { (Reference } \\
1\end{array}$ & $\begin{array}{l}<0.001(<0.001, \\
>999.999)\end{array}$ \\
2 & $3.54(0.30,8.03)$ & \\
3 & $3.09(1.03,9.01)$ & $1.88(0.48,7.39)$ & $1.00^{*}$ (Reference*) \\
4 & $2.31(0.88,6.06)$ & $1.78(0.49,6.40)$ & $2.89(0.57,14.72)$ \\
5 & $2.95(1.16,7.50)$ & $3.53(1.24,10.07)$ & $5.36(1.41,20.38)$ \\
6 & $2.03(0.60,6.86)$ & $1.67(0.38,7.37)$ & $1.40(0.14,13.88)$ \\
7 & $3.63(1.42,9.24)$ & $1.97(0.62,6.27)$ & $2.75(0.60,12.60)$ \\
8 & $5.71(2.32,14.07)$ & $3.37(1.15,9.87)$ & $5.85(1.51,22.71)$ \\
9 & $3.67(1.30,10.36)$ & $2.14(0.59,7.79)$ & $4.91(1.06,22.80)$ \\
10 & $3.00(1.25,7.18)$ & $2.94(1.07,8.07)$ & $3.95(1.08,14.48)$ \\
13 & $3.18(1.22,8.31)$ & $2.95(0.97,9.00)$ & $4.17(1.01,17.30)$ \\
16 & $3.83(1.40,10.47)$ & $4.09(1.31,12.79)$ & $8.60(2.17,34.02)$
\end{tabular}

*There were no cases of LE in Framingham Scores of 0 and 1, so we collapsed $0,1,2$ into one reference category in order to generate stable estimates

health outcomes (lateral elbow symptoms and physical examination findings) thus support the overall impact of the results for LE.

Individual cardiovascular disease risk factors have been previously reported as risks for LE. A prior case-control study found peripheral vascular disease and diabetes mellitus were both associated with LE [68]. Diabetes mellitus has been reported to be a LE risk [12], as well as chronic hyperglycemia [79]. Three studies have suggested prior smoking was a risk for LE [12, 80, 81]. Two studies reported a trend of increasing LE risk with obesity $[12,19]$, although another found it to not be a risk [80]. Our study failed to find BMI as a risk factor. That difference may possibly be due to the greater ability to control for more factors in this study. It is noteworthy that the Framingham CVD risk factor model does not include obesity.

This study systematically evaluated the prevalence of lateral elbow symptoms, examination findings and LE. The point prevalence estimate for each of these was $15.0 \%, 14.5 \%$ and $6.6 \%$, respectively. These prevalence estimates are higher than most other reviewed studies and unsurprising considering the carefully structured, individualized interviews and physical examinations. Additionally, a significant proportion of worker's jobs was physically demanding and may have produced some increases in the prevalence rates.

This line of research may have implications for both clinical care and population management. Should CVD risks be confirmed as significant risks for common musculoskeletal disorders (MSDs), patients presenting with one disorder would likely be candidates for more intensive CVD risk management, potentially to prevent both MSDs and CVD. Additionally, effective health promotion disease prevention programs could have greater efficacy beyond traditional cardiovascular diseases to include MSDs. Still, there is considerable research required before interventional programs could be enacted for purposes of addressing MSD risks as CVD risks.

\section{Strengths of this study}

Strengths of this study include the large sample size, multi-state population, systematic measurement of lateral elbow pain and physical examination findings, measured BMI, and measured blood pressure. The systematic measurement of all these factors in a large population-based study is a unique strength. The systematic approach to use a modified Framingham CVD risk score to quantify cardiovascular risks is another strength. The adjustment for laboriously quantified job physical risk factors is an extraordinarily rare strength and helps to remove that potential confounder.

\section{Limitations of this study}

Weaknesses include the cross sectional design, although the extreme costs to measure, videotape and quantify job physical factors makes a prospective cohort study to duplicate these results with sufficient powering difficult. A cross sectional design largely precludes causal inference. The large proportion of workers from the manufacturing sector is a potential limitation, although this study included workers from the services and healthcare sectors, and it seems unlikely that the source of patients should materially influence the CVD scores or alter their relationships. The primary exposure in this study is a modified Framingham CVD risk score. To address that weakness, we performed the analyses on the subset of data with complete blood pressure measurements, hypertensive histories and cholesterol histories; those analyses also showed strong, meaningful associations between CVD risk and lateral epicondylitis.

Prospective cohort analyses are needed to confirm these results in incidence data and duplicated elsewhere. Studies reporting changes in LE prevalence and/or incidence rates based on CVD risk factor modification are also needed.

\section{Conclusions}

This study suggests there is a strong association between CVD risk score and LE that demonstrates strength of association, consistency with other studies evaluating individual CVD factors, a biological gradient response, and biological plausibility. This association remains after adjustment for known and suspected confounders, including meticulous quantification of job physical factors. These results suggest a strong, potentially modifiable 
disease mechanism. However, whether CVD risk factor modification reduces risk of LE requires further investigation.

\section{Abbreviations}

BMI: Body Mass Index; Cl: Confidence Interval; CTS: Carpal Tunnel Syndrome; CVD: Cardiovascular Disease; LE: Lateral Epicondylitis; MSD: Musculoskeletal Disorder; NIOSH: National Institute for Occupational Safety and Health; OR: Odds Ratio; SI: Strain Index

\section{Acknowledgements}

The authors acknowledge the over 1,800 workers who volunteered to participate in these studies. The authors also wish to acknowledge the many years of work by the research teams, including the dozens of technicians, assistants, and other research personnel from the study groups that made the collection of the data for this manuscript possible.

\section{Funding}

This work was supported, in part, by grants from the National Institute for Occupational Safety and Health (NIOSH/CDC) grant number 1R01OH010474-01 and NIOSH Education and Research Center training grant number T42/ CCT810426-10.

\section{Availability of data and materials}

The datasets used and/or analyzed during the current study are available from the corresponding author upon reasonable request. Data will be shared to the extent that they do not identify workers and were paid by grants.

\section{Authors' contributions}

All authors contributed equally to the writing of this work. All authors have read and approved the final manuscript. Below is a detail of each author's specific research contributions: $\mathrm{KTH}, \mathrm{MD}, \mathrm{MPH}, \mathrm{Pl}$ in Utah. Designed field measures in UT and WI. MST, PhD, MSPH, Coordination of teams, computerization of instruments, analyses of data. JK, PhD. Ergonomic lead for job measurements in WI. AM, PhD Ergonomic lead for job measurements in UT. SB, PhD, Ergonomic lead for job measurements in WA. BS, PhD, PI in WA Designed health outcomes. EMW, MD, MPH, Field measurements of workers in UT, oversight of other team members in UT. RK, DO Field measurements of workers in UT, oversight of other team members in UT. JF, MD, Field measurements of workers in Wl, oversight of other team members in WI. DLD, MD MPH, Field measurements of workers in Wl, oversight of other team members in WI. AG, PhD, PI. Overall coordination of job measures across all studies.

\section{Competing interests}

The authors declare that they have no competing interests.

\section{Consent for publication}

Not applicable.

\section{Ethics approval and consent to participate}

The Institutional Review Boards of the University of Utah, University of Wisconsin-Milwaukee, and the State of Washington approved this study. Informed consent was obtained from all participants.

\section{Publisher's Note}

Springer Nature remains neutral with regard to jurisdictional claims in published maps and institutional affiliations.

\section{Author details}

${ }^{1}$ Rocky Mountain Center for Occupational and Environmental Health (RMCOEH), School of Medicine, University of Utah, 391 Chipeta Way Suite C, Salt Lake City, UT 84108, USA. ${ }^{2}$ Department of Occupational Science \& Technology, College of Health Sciences, University of Wisconsin-Milwaukee, PO Box 413, Milwaukee, WI 53201, USA. ${ }^{3}$ Department of Mechanical Engineering, University of Utah, 1495 East 100 South, Salt Lake City, UT 84112, USA. ${ }^{4}$ Safety and Health Assessment and Research for Prevention (SHARP) Program, 243 Israel Road SE Bldg 3, Tumwater, WA 98501, USA. ${ }^{5}$ Physical Medicine and Rehabilitation, University of Utah, 30 North 1900 East, Salt Lake City, UT 84132, USA. 'United Occupational Medicine, 9555 76th St.,
Pleasant Prairie, WI 53158, USA. ${ }^{7}$ Clement J Zablocki VA Medical Center, Compensation \& Pension Department, 5000 W National Avenue, Milwaukee, WI 53295, USA.

Received: 7 November 2016 Accepted: 22 May 2017

Published online: 30 May 2017

\section{References}

1. Pullopdissakul S, Ekpanyaskul C, Taptagaporn S, Bundhukul A, Thepchatri A. Upper extremities musculoskeletal disorders: prevalence and associated ergonomic factors in an electronic assembly factory. Int J Occ Med Environ Health. 2013;26(5):751.

2. Tajika T, Kobayashi T, Yamamoto A, Kaneko T, Takagishi K. Prevalence and risk factors of lateral epicondylitis in a mountain village in Japan. J Orthop Surg (Hong Kong). 2014;22(2):240.

3. Herquelot E, Bodin J, Roquelaure Y, Ha C, Leclerc A, Goldberg M, et al. Work-related risk factors for lateral epicondylitis and other cause of elbow pain in the working population. Amer J Indust Med. 2013;56(4):400.

4. Bugajska J, Zolnierczyk-Zreda D, Jedryka-Goral A, Gasik R, Hildt-Ciupinska K, Malinska M, et al. Psychological factors at work and musculoskeletal disorders: a one year prospective study. Rheum Int. 2013;33(12):2975.

5. Ozdolap S, Emre U, Karamercan A, Sarikaya S, Kokturk F. Upper limb tendinitis and entrapment neuropathy in coal miners. Ame J Indust Med. 2013;56(5):569.

6. Battevi N, Menoni O, Vimercati C. The occurrence of musculoskeletal alterations in worker populations not exposed to repetitive tasks of the upper limbs. Ergo. 1998;41(9):1340.

7. Rosenbaum DA, Grzywacz JG, Chen H, Arcury TA, Schulz MR, Blocker JN, et al. Prevalence of epicondylitis, rotator cuff syndrome, and low back pain in Latino poultry workers and manual laborers. Amer J Indust Med. 2013;56(2): 226.

8. Kuklo TR, Bridwell KH, Lewis SJ, Baldus C, Blanke K, Iffrig TM, et al. Minimum 2-year analysis of sacropelvic fixation and L5-S1 fusion using S1 and iliac screws. Spine. 2001;26(18):1976.

9. Fan ZJ, Silverstein BA, Bao S, Bonauto DK, Howard NL, Spielholz PO, et al. Quantitative exposure-response relations between physical workload and prevalence of lateral epicondylitis in a working population. Amer J Indust Med. 2009;52(6):479.

10. Kryger Al, Lassen CF, Andersen JH. The role of physical examinations in studies of musculoskeletal disorders of the elbow. Occ Environ Med. 2007; 64(11):776.

11. Roquelaure $\mathrm{Y}, \mathrm{Ha}$ C, Leclerc $\mathrm{A}$, Touranchet $\mathrm{A}$, Sauteron M, Melchior M, et al. Epidemiologic surveillance of upper-extremity musculoskeletal disorders in the working population. Arth Rheum. 2006;55(5):765.

12. Shiri R, Viikari-Juntura E, Varonen H, Heliovaara M. Prevalence and determinants of lateral and medial epicondylitis: a population study. Ameri Epi. 2006;164(11):1065.

13. Salaffi F, De Angelis R, Grassi W. Prevalence of musculoskeletal conditions in an Italian population sample: results of a regional community-based study. I. The MAPPING study. Clin Exp Rheum. 2005;23(6):819.

14. Werner RA, Franzblau A, Gell N, Hartigan A, Ebersole M, Armstrong TJ. Predictors of persistent elbow tendonitis among auto assembly workers. J Occ Rehab. 2005;15(3):393.

15. Walker-Bone K, Palmer KT, Reading I, Coggon D, Cooper C. Prevalence and impact of musculoskeletal disorders of the upper limb in the general population. Arth Rheum. 2004:51(4):642.

16. Ono Y, Nakamura R, Shimaoka M, Hiruta S, Hattori Y, Ichihara G, et al. Epicondylitis among cooks in nursery schools. Occ Environ Med. 1998;55(3): 172.

17. Chiang HC, Ko YC, Chen SS, YU HS, Wu TN, Chang PY. Prevalence of shoulder and upper-limb disorders among workers in the fish-processing industry. Scan J Work Environ Health. 1993;19(2):126.

18. Roto P, Kivi P. Prevalence of epicondylitis and tenosynovitis among meatcutters. Scan J Work Environ Health. 1984;10(3):203.

19. Descatha A, Dale AM, Jaegers L, Herquelot E, Evanoff B. Self-reported physical exposure association with medial and lateral epicondylitis incidence in a large longitudinal study. Occ Environ Med. 2013;70(9):670.

20. Descatha A, Leclerc A, Chastang JF, Roquelaure Y. Medial epicondylitis in occupational settings: prevalence, incidence and associated risk factors. J Occup Environ Med. 2003;45(9):993. 
21. Sanders TL Jr, Maradit Kremers H, Bryan AJ, Ransom JE, Smith J, Morrey BF. The epidemiology and health care burden of tennis elbow: a populationbased study. Amer J Sports Med. 2015;43(5):1066.

22. Garg A, Kapellusch JM, Hegmann KT, Thiese MS, Merryweather AS, Wang YC, et al. The strain index and TLV for HAL: risk of lateral epicondylitis in a prospective cohort. Amer J Indust Med. 2014;57(3):286.

23. Kurppa K, Viikari-Juntura E, Kuosma E, Huuskonen M, Kivi P. Incidence of tenosynovitis or peritendinitis and epicondylitis in a meat-processing factory. Scan J Work Environ Health. 1991;17(1):32.

24. Pascarelli EF, Hsu YP. Understanding work-related upper extremity disorders: clinical findings in 485 computer users, musicians, and others. J Occ Rehab. 2001;11(1):1.

25. Ries C, Franke S, Dietrich F, Jakubowitz E, Dehlinger F, Hollinger B. Transosseous refixation of the common extensor muscle tendons in chronic lateral epicondylitis with and without additional reconstruction of the LUCL-a retrospective evaluation of 101 patients. Zeitschrift fur Orthopadie und Unfallchirurgie. 2013;151(3):296.

26. Schmushkevich KL. Myofascial pain in lateral epicondylagia: a review. J Bodyw Mov Ther. 2013;17(4):434

27. Fernandez-Carnero J, Fernandez-de-Las-Penas C, de la Llave-Rincon Al, Ge $H Y$, Arendt-Nielsen L. Prevalence of and referred pain from myofascial trigger points in the forearm muscles in patients with lateral epicondylalgia. Clin J Pain. 2007;23(4):353.

28. Goldie I. Epicondylitis lateralis humeri (epicondylalgia or tennis elbow). A pathogenetical study. Acta chirurgica Scandinavica Supplementum. 1964; 57(SUPPL 339):1+

29. Nirschl RP, Pettrone FA. Tennis elbow. The surgical treatment of lateral epicondylitis. J Bone Joint Surg. 1979;61(6A):832.

30. Hegmann KT, Thiese MS, Kapellusch J, Merryweather AS, Bao S, Silverstein B, et al. Association between cardiovascular risk factors and carpal tunnel syndrome in pooled occupational cohorts. J Occup Environ Med. 2016;58(1): 87.

31. Doran A, Gresham GA, Rushton N, Watson C. Tennis elbow. A clinicopathologic study of 22 cases followed for 2 years. Acta Orthop Scand 1990;61(6):535

32. Goldberg EJ, Abraham E, Siegel I. The surgical treatment of chronic lateral humeral epicondylitis by common extensor release. Clin Ortho Related Res. 1988:233:208.

33. Regan W, Wold LE, Coonrad R, Morrey BF. Microscopic histopathology of chronic refractory lateral epicondylitis. Amer J Sports Med. 1992;20(6):746.

34. Peterson M, Butler S, Eriksson M, Svardsudd K. A randomized controlled trial of exercise versus wait-list in chronic tennis elbow (lateral epicondylosis). Upsala J Med Sci. 2011;116(4):269.

35. Kim JW, Chun CH, Shim DM, Kim TK, Kweon SH, Kang HJ, et al. Arthroscopic treatment of lateral epicondylitis: comparison of the outcome of ECRB release with and without decortication. Knee Surg Sports Trauma Arthro. 2011;19(7):1178

36. Buchbinder R, Johnston RV, Barnsley L, Assendelft WJ, Bell SN, Smidt N. Surgery for lateral elbow pain. Cochrane Data Sys Rev. 2011;3:CD003525.

37. Hegmann KT, Hoffman HE, Belcourt RM, Byrne K, Glass L, Melhorn JM, et al. ACOEM practice guidelines: elbow disorders. J Occup Environ Med. 2013; 55(11):1365.

38. Singh JA. Use of botulinum toxin in musculoskeletal pain. F1000Res. 2013;2: 52.

39. Herquelot E, Gueguen A, Roquelaure $Y$, Bodin J, Serazin $\mathrm{C}, \mathrm{Ha}$ C, et al. Workrelated risk factors for incidence of lateral epicondylitis in a large working population. Scan J Work Environ Health. 2013;39(6):578.

40. Wolf JM, Mountcastle S, Burks R, Sturdivant RX, Owens BD. Epidemiology of lateral and medial epicondylitis in a military population. Mil Med. 2010;175(5):336

41. Leclerc A, Landre MF, Chastang JF, Niedhammer I, Roquelaure Y. Upper-limb disorders in repetitive work. Scan J Work Environ Health. 2001;27(4):268.

42. Haahr JP, Andersen JH. Prognostic factors in lateral epicondylitis: a randomized trial with one-year follow-up in 266 new cases treated with minimal occupational intervention or the usual approach in general practice. Rheum (Oxford). 2003;42(10):1216.

43. Hakim AJ, Cherkas LF, Spector TD, MacGregor AJ. Genetic associations between frozen shoulder and tennis elbow: a female twin study. Rheum (Oxford). 2003;42(6):739.

44. Altinisik J, Meric G, Erduran M, Ates O, Ulusal AE, Akseki D. The BstUI and Dpnll variants of the COL5A1 gene are associated with tennis elbow. Amer J Sports Med. 2015;43(7):1784.
45. Dines JS, Bedi A, Williams PN, Dodson CC, Ellenbecker TS, Altchek DW, et al. Tennis injuries: epidemiology, pathophysiology, and treatment. J Amer Acad Ortho Surg. 2015;23(3):181.

46. Pieber K, Angelmaier L, Csapo R, Herceg M. Acute injuries and overuse syndromes in sport climbing and bouldering in Austria: a descriptive epidemiological study. Wien Klin Wochenschr. 2012;124(11-12):357.

47. Bayes MC, Wadsworth LT. Upper extremity injuries in golf. Phys Sports Med. 2009;37(1):92.

48. Kitai E, Itay S, Ruder A, Engel J, Modan M. An epidemiological study of lateral epicondylitis (tennis elbow) in amateur male players. Ann Chir Main. 1986;5(2):113.

49. Nirschl RP. Tennis elbow: further considerations. J Sports Med. 1975;3(1):48.

50. Bollen SR. Upper limb injuries in elite rock climbers. J Royal Coll Surg Edinburgh. 1990;35(6 Suppl):S18.

51. Hamilton PG. The prevalence of humeral epicondylitis: a survey in general practice. J Royal Coll Gen Prac. 1986;36(291):464.

52. Arcury TA, Cartwright MS, Chen H, Rosenbaum DA, Walker FO, Mora DC, et al. Musculoskeletal and neurological injuries associated with work organization among immigrant Latino women manual workers in North Carolina. AmeJ Indust Med. 2014;57(4):468.

53. van Rijn RM, Huisstede BM, Koes BW, Burdorf A. Associations between workrelated factors and specific disorders at the elbow: a systematic literature review. Rheum (Oxford). 2009:48(5):528.

54. Haahr JP, Andersen JH. Physical and psychosocial risk factors for lateral epicondylitis: a population based case-referent study. Occ Environ Med. 2003;60(5):322.

55. Ritz BR. Humeral epicondylitis among gas- and waterworks employees. Scan J Work Environ Health. 1995;21(6):478.

56. Luopajarvi T, Kuorinka I, Virolainen M, Holmberg M. Prevalence of tenosynovitis and other injuries of the upper extremities in repetitive work. Scan J Work Environ Health. 1979;5(suppl 3):48.

57. Dimberg L. The prevalence and causation of tennis elbow (lateral humeral epicondylitis) in a population of workers in an engineering industry. Ergo. 1987;30(3):573.

58. Kurppa K, Waris P, Rokkanen P. Tennis elbow. Lateral elbow pain syndrome. Scan J Work Environ Health. 1979;5(suppl 3):15.

59. Viikari-Juntura E, Kurppa K, Kuosma E, Huuskonen M, Kuorinka I, Ketola R, et al. Prevalence of epicondylitis and elbow pain in the meat-processing industry. Scan J Work Environ Health. 1991;17(1):38.

60. Dryson EW, Walls CB. The distribution of occupations in two populations with upper limb pain. IntJ Occ Environ Health. 2001;7(3):201.

61. Grzywacz JG, Arcury TA, Mora D, Anderson AM, Chen H, Rosenbaum DA, et al. Work organization and musculoskeletal health: clinical findings from immigrant Latino poultry processing and other manual workers. J Occup Environ Med. 2012:54(8):995

62. Descatha A, Roquelaure Y, Chastang JF, Evanoff B, Cyr D, Leclerc A. Description of outcomes of upper-extremity musculoskeletal disorders in workers highly exposed to repetitive work. J Hand Surg. 2009;34(5):890.

63. Viikari-Juntura E, Shiri R, Solovieva S, Karppinen J, Leino-Arjas P, Varonen H, et al. Risk factors of atherosclerosis and shoulder pain-is there an association? A systematic review. Eur J Pain. 2008;12(4):412.

64. Moore JS, Garg A. The strain index: a proposed method to analyze jobs for risk of distal upper extremity disorders. Amer Indust Hyg Assoc J. 1995;56(5): 443.

65. Garg A, Hegmann KT, Wertsch JJ, Kapellusch J, Thiese MS, Bloswick D, et al. The WISTAH hand study: a prospective cohort study of distal upper extremity musculoskeletal disorders. BMC Musc Dis. 2012;13:90.

66. Garg A, Kapellusch J, Hegmann K, Wertsch J, Merryweather A, DeckowSchaefer G, et al., Team tWHSR. The strain index (SI) and threshold limit value (TLV) for hand activity level (HAL): risk of carpal tunnel syndrome (CTS) in a prospective cohort. Ergo. 2012;55(4):396.

67. D'Agostino RB, Vasan RS, Pencina MJ, Wolf PA, Cobain M, Massaro JM, et al. General cardiovascular risk profile for use in primary care the Framingham Heart Study. Circ. 2008;117(6):743.

68. Font YM, Castro-Santana LE, Nieves-Plaza M, Maldonado M, Mayor AM, Vila LM. Factors associated with regional rheumatic pain disorders in a population of Puerto Ricans with diabetes mellitus. Clin Rheum. 2014;33(7): 995.

69. Gaida JE, Alfredson L, Kiss ZS, Wilson AM, Alfredson H, Cook JL. Dyslipidemia in Achilles tendinopathy is characteristic of insulin resistance. Med Sci Sports and Ex. 2009;41(6):1194. 
70. Heckman D, Gluck G, Parekh S. Tendon disorders of the foot and ankle, Part 2: Achilles tendon disorders. Amer J Sports Med. 2009;37(6):1223.

71. Reddy S, Pedowitz D, Parekh S, Omar I, Wapner K. Surgical treatment for chronic disease and disorders of the Achilles tendon. J Amer Acad Ortho Surg. 2009;17(1):3.

72. Applegate K, Thiese M, Merryweather A, Kapellusch J, Drury D, Wood E, et al. Association between cardiovascular disease risk factos and rotator cuff tendinopathy. J Occ Environ Med. 2017;59(2):154.

73. Hegmann K. Common neuromusculoskeletal disorders. New York: Plenum Press; 1998.

74. Viikari-Juntura E, Shiri R, Solovieva S, Karppinen J, Leino-Arjas P, varonen $H_{\text {, }}$ et al. Risk factors of atherosclerosis and shoulder pain- Is there an assocation? A systematic review. Eur J Pain. 2008;12(4):412.

75. Leander K, Hallqvist J, Reuterwall C, Ahlbom A, de Faire U. Family history of coronary heart disease, a strong risk factor for myocardial infarction interacting with other cardiovascular risk factors: results from the Stockholm Heart Epidemiology Program (SHEEP). Epi. 2001;12(2):215.

76. Wolf PA, D'Agostino RB, Belanger AJ, Kannel WB. Probability of stroke: a risk profile from the Framingham Study. Stroke. 1991;22(3):312.

77. Celis-Morales CA, Perez-Bravo F, Ibanez L, Salas C, Bailey ME, Gill JM. Objective vs. self-reported physical activity and sedentary time: effects of measurement method on relationships with risk biomarkers. PLoS One. 2012;7(5):e36345

78. Brenner H, Savitz DA. The effects of sensitivity and specificity of case selection on validity, sample size, precision, and power in hospital-based case-control studies. Amer J Epi. 1990;132(1):181.

79. Otoshi K, Takegami M, Sekiguchi M, Onishi Y, Yamazaki S, Otani K, et al. Chronic hyperglycemia increases the risk of lateral epicondylitis: the Locomotive Syndrome and Health Outcome in Aizu Cohort Study (LOHAS). Springer Plus. 2015;4:407.

80. Titchener AG, Fakis A, Tambe AA, Smith C, Hubbard RB, Clark DI. Risk factors in lateral epicondylitis (tennis elbow): a case-control study. J Hand Surg. 2013:38(2):159.

81. Michienzi AE, Anderson CP, Vang S, Ward CM. Lateral epicondylitis and tobacco use: a case-control study. lowa Ortho J. 2015;35:114.

\section{Submit your next manuscript to BioMed Central and we will help you at every step:}

- We accept pre-submission inquiries

- Our selector tool helps you to find the most relevant journal

- We provide round the clock customer support

- Convenient online submission

- Thorough peer review

- Inclusion in PubMed and all major indexing services

- Maximum visibility for your research

Submit your manuscript at www.biomedcentral.com/submit 